\title{
Muscovite MDD: In vacuo argon release via volume diffusion
}

\author{
MATTHEW T. HEIZLER ${ }^{1}$, MARK E. HOLLAND ${ }^{2}$ AND SEAN \\ P. $\mathrm{LONG}^{3}$
}

${ }^{1}$ New Mexico Bureau of Geology, 801 Leroy Place, Socorro, NM, 87801, matt.heizler@nmt.edu

${ }^{2}$ West Texas A\&M Univ., Department of Life, Earth and Environmental Sciences, 2403 Russel Long Blvd., Canyon, TX, 79015, meholland@wtamu.edu

${ }^{3}$ Sean P. Long, School of the Environment, Washington State University, PO Box 642812, Pullman WA 99164

Both field and laboratory ${ }^{40} \mathrm{Ar} /{ }^{39} \mathrm{Ar}$ data of muscovite indicate that argon release can be well described by volume diffusion in nature and under laboratory conditions. Extracting meaningful continuous thermal histories from about 375 to $275^{\circ} \mathrm{C}$ seems possible and represents a significant advance for thermochronology. Observations that support a multiple diffusion domain (MDD) mechanism for muscovite are:

1) Age spectra commonly have inflections indicative of MDD behavior. 2) Arrhenius data derived from ${ }^{39} \mathrm{Ar}$ loss are well described by an MDD model. 3) There is a direct relationship between physical grain size and degassing behavior. 4) Model age spectra closely match measured age spectra utilizing a MDD model. 5) Known laboratory-induced thermal histories are recovered with the MDD approach. 6) Thermal histories derived via the MDD approach are in agreement with multiple other thermochronometers derived from a single sample. Multiple aliquots of variably sized muscovite were degassed at temperatures between $\sim 600$ and $800^{\circ} \mathrm{C}$ for $1 \mathrm{hr}$ to 10 days in vacuo. These aliquots were subsequently irradiated and step-heated for age spectrum determination. As predicted by volume diffusion, initial steps yield apparent ages of zero Ma and subsequently increase in age. The spectra have a characteristic sinuous shape conforming to a multiple diffusion length scale distribution as do the Arrhenius plots. Importantly, finer grain aliquots exposed to the same thermal history have lost greater degrees of ${ }^{40} \mathrm{Ar} *$ compared to coarser grained aliquots. Also, the frequency factors based on ${ }^{39} \mathrm{Ar}$ release for fine material are greater than for coarser material. Extracting the diffusion domain distribution from the release of ${ }^{39} \mathrm{Ar}$ and imposing the known degassing thermal history reveals a model age spectrum that very well matches the measured age spectrum. This consistency is compelling evidence to support a diffusion model. Importantly, MDD muscovite application to geological studies where multiple thermochronometers are employed shows consistency of the derived thermal histories. Work needs to be done, but at this point, if not diffusion then what? 